\title{
"NO BRAZIL A COLHEITA DAS GRAÇAS NÃO É MENOS PROFUSA QUE A DO CAFÉ": AS EXPOSIÇÕES DA INDÚSTRIA NO BRASIL DOS ANOS 1860
}

Mônica Martins ${ }^{1}$

Resumo: $O$ artigo discute o significado econômico das exposições nacionais como parte das grandes exposições universais do século XIX. Com análise específica do caso brasileiro, traça uma discussão sobre o caráter dessas exposições nacionais no país. Em seguida, realiza uma análise de fontes, a partir de uma sátira política da Semana Illustrada e dos relatórios do Júri das Exposições Nacionais de 1861 e de 1866. Destaca com as fontes os elementos críticos à participação do país nas exposições, mostrando também como os relatórios se constituíram em ricas fontes de pesquisa sobre decisões econômicas adotadas pelo governo imperial.

Palavras-chave: Exposições. Café. Economia. Século XIX. Brasil Império.

\section{"IN BRAZIL THE HARVEST OF GRACES IS NO LESS PROFUSE THAN THAT OF COFFEE": THE INDUSTRY EXHIBITIONS IN BRAZIL IN THE 1860S}

Abstract: The article is about the economic significance of the national exhibitions as part of the great universal exhibitions of the nineteenth century. With specific analysis of the Brazilian case, it draws a discussion about the character of these national exhibitions in the country. Then it analyzes sources from a political satire of Semana Illustrada and the reports of the Jury of National Exhibitions of 1861 and 1866. The sources emphasize the critical aspects to the Brazil's participation in the exhibitions, also showing how the reports became rich sources of research on economic decisions adopted by the imperial government.

Keywords: Exhibitions. Coffee; Economy. XIX century. Brazil Empire.

\section{"EN BRASIL, LA COSECHA DE GRACIAS NO ES MENOS PROFUSA QUE LA DEL CAFÉ": LAS EXPOSICIONES DE LA INDUSTRIA EN BRASIL EN LA DÉCADA DE 1860}

Resumen: El artículo analiza la importancia económica de las exposiciones nacionales como parte de las grandes exposiciones universales del siglo XIX. Con un análisis específico del caso brasileño, traza una discusión sobre el carácter de estas exposiciones nacionales en el país. Luego, realiza un análisis de las fuentes, basado en una sátira política de la Semana llustrada y los informes del Jurado Nacional de Exposiciones de 1861 y 1866. Destaca con las fuentes los elementos críticos para la participación del país en las exposiciones, y muestra también cómo los informes se han convertido en ricas fuentes de investigación sobre las decisiones económicas tomadas por el gobierno imperial.

\footnotetext{
1 Universidade Federal Rural do Rio de Janeiro, Departamento de História, Nova Iguaçu, Brasil,
} monicamartins@ufrrj.br, https://orcid.org/0000-0003-0917-3437 
Palabras clave: Exposiciones. Café. Economía. Siglo XIX. Imperio de Brasil.

\section{As Exposições Universais e seus significados}

A historiografia internacional é profusa em estudos sobre as grandes Exposições Universais, que se realizaram principalmente na Europa e nos Estados Unidos ${ }^{2}$. Essas exibições internacionais foram impulsionadas por eventos de caráter nacional, tanto em sua gênese, a partir das exposições nacionais francesas, como na segunda parte dos oitocentos elas se tornaram uma forma de organizar antecipadamente a participação dos respectivos países nos eventos internacionais. Assim, a partir delas se fazia a seleção de produtos e produtores e eram selecionados os melhores exemplares da produção nacional que deveriam ser exibidos no exterior. Tudo isso indica que elas tiveram um intuito eminentemente comercial, num momento decisivo da consolidação dessas relações a nível mundial. ${ }^{3}$

O caráter nacional ${ }^{4}$ das Exposições já foi tratado por vários autores, enfatizando tanto a contribuição desses eventos "domésticos" como forma de organização preliminar dos países para a participação internacional, quanto a projeção de nacionalismos e projetos políticos diversos associados a elas. ${ }^{5} \mathrm{Na}$ primeira metade do século XIX foram disseminadas pela Europa exposições de caráter nacional, fomentando internamente projetos diversos de expansão territorial ou comercial, integração regional/nacional ou afirmação de projetos políticos em foco. Os franceses, entre 1798 e 1855, realizaram onze exposições nacionais, marcadas pelas disputas com a Inglaterra e tornaram seus eventos referências internacionais na forma de organizar regionalmente. ${ }^{6}$ Todas as exposições até os anos 1850 seguiam uma tradição que aliava

2 SANJAD, Nelson. Exposições internacionais: uma abordagem historiográfica a partir da América Latina, Revista História, Ciências, Saúde - Manguinhos, v.24, n.3, jul.-set., 2017, p.785-826; FINDLING, John E.; PELLE, Kimberly D. Historical Dictionary of World's Fairs and Expositions, 1851-1988. Westport, Connecticut: Greenwood Press, 1990; PLUM, Werner. Exposições no século XIX: espetáculos da transformação sociocultural. Bonn: Friedrich-Ebert-Stiftung, 1979.

${ }^{3}$ GREENHALGH, Paul. Ephemeral Vistas: The Expositions Universelles, Great Exhibitions and World's Fairs, 1851-1939. Manchester: Manchester University Press, 1988, p. 22.

${ }^{4} \mathrm{Em}$ face dos limites do artigo não entrarei aqui no debate das concepções sobre nação e nacionalismo no século XIX, que tem merecido ampla gama de estudos acadêmicos.

${ }^{5}$ FILIPOVÁ, Marta. "The Margins of Exhibitions and Exhibitions Studies", in: FILIPOVÁ, M. (Ed.) Cultures of International Exhibitions 1840-1940. Burlington: Ashgate, 2015.

${ }^{6}$ SILVA, José Luiz Werneck. As arenas pacíficas do Progresso. Tese de Doutorado em História. 2 vols. Niterói: Universidade Federal Fluminense, 1992, p. 89. 
o caráter oriundo das feiras medievais, ${ }^{7}$ como espaços de vendas de produtos, com 0 novo aspecto que adquiriam as exposições da indústria: exibição e divulgação de matérias-primas, de produtos e invenções relacionadas ao mundo agrícola, da disponibilidade dos recursos naturais e da produção fabril de cada país.

A quantidade de exposições foi crescente ao longo dos anos, iniciativas que eram acompanhadas pela rápida expansão industrial. Segundo Hobsbawm, os anos 1840 foram um período em que a ciência e a engenharia agrícola atingiram sua maturidade na Inglaterra, marcado pela avassaladora expansão das ferrovias e do capital associado ao investimento nelas. ${ }^{8}$ Por outro lado, após a enxurrada de guerras e revoluções que varreram a Europa até anos 1830, esse período mostrou uma fase de consolidação de uma nova ordem onde a burguesia se assumia definitivamente na condução política dos Estados, com governos exercidos por banqueiros, altos industriais ou altos funcionários civis. ${ }^{9}$ O final da década de 1840 foi marcada ainda por revoluções na Europa e pela fermentação de movimentos nacionalistas. Mas o crescimento dos movimentos sociais e do operariado despertavam a preocupação da burguesia que alcançava o poder, o que para ela sinalizava a necessidade de ações de "pacificação de classe", tais como seriam espetacularmente marcadas pelas exposições da indústria ao longo dos oitocentos.

Ao tratar dos aspectos políticos assumidos pelas exposições, Greenhalgh ${ }^{10}$ sinaliza que a Exposição de 1851 não representou uma celebração. O príncipe Albert, figura central em toda a estrutura executiva da Great Exhibition Londrina tinha clareza de que não havia uma ideia hegemônica sobre a unidade britânica. Nesse movimento de estruturação de unidade nacional, o cartismo e o sindicalismo vinham mostrando a força dos trabalhadores ingleses e uma feição nova de reivindicação de direitos sociais e dos trabalhadores, demonstrando que a questão da exploração e do empobrecimento também era um quadro que marcava a formação dessa nacionalidade britânica. Portanto, concluiu que essa exposição se constituiu numa ação antirrevolucionária, um espetáculo grandioso e eloquente que serviu para intimidar ou mudar o foco das grandes insurreições do período, projetando para o mundo a ideia de modernidade e progresso britânica.

\footnotetext{
${ }^{7}$ BANCROFT, Hubert Howe. The book of the fair. an historical and descriptive presentation of the world's Science, art and industry, as viewed through the Columbian Exposition at Chicago in 1893. Chicago/São Francisco: The Bancroft Company, Publishers, 1893, part 1.

${ }^{8}$ HOBSBAWM, Eric. The Age of Revolution,1789-1898. New York: Vintage Books, 1996, p. 99-102.

9 Ibidem, p.120.

10 GREENHALGH, Paul. Ephemeral Vistas: The Expositions Universelles, Great Exhibitions and World's Fairs, 1851-1939. Manchester: Manchester University Press, 1988.
} 
A preocupação em tornar o cotidiano dos trabalhadores um dos focos das exposições se manteve nos eventos seguintes, que foram denominados "Exposições do trabalho e da Indústria". Essa iniciativa visava agregar às amostras também aspectos relacionados ao "mundo do trabalho", o que ficou mais explícito a partir de 1867, em Paris. Essa preocupação já sinalizada desde a década anterior aumentou depois das greves de 1864, se tornando uma questão central na organização política das exposições europeias a partir da década de 1860. Essa projeção do lugar do trabalhador dentro da disciplina fabril foi bem representada nos eventos, por exemplo, pelas exibições sobre os cuidados com a higiene, a moradia e a alimentação operária. ${ }^{11}$ Como bem apontado por Margareth Pereira sobre as modificações no perfil das exposições ao longo desse período, indicado pela característica da exposição de 1867, em Paris, descreve:

Em 1867, as exposições já haviam se tornado gigantescos aparatos de puro artifício - cidade dentro da cidade engastadas as margens da vida urbana monótona e rotineira das fábricas e vilas operárias. Ao lado dos enormes edifícios que reuniam a produção do conjunto dos países e dos anexos destinados às máquinas e agricultura, centenas de quiosques e de pavilhões isolados ocupados por diferentes nações mergulhavam o visitante num espaço de sedução do qual só alguns poucos conseguiam escapar. O aspecto de bazar ou de um parque de diversões dominava a atmosfera do Champs de Mars, rivalizando com a racionalidade do colossal edifício elíptico desenhado por Le Play. No parque, as comissões estrangeiras procuram erguer modelos reduzidos de construções que possam dar uma imagem sintética dos seus respectivos países, caracterizando "seus hábitos e sua civilização", nas palavras de um comentarista da época. ${ }^{12}$

Todo esse aparato de sedução estética e arquitetônica se misturava ao enorme conjunto de visitantes que a cada ano lotava a visita aos pavilhões das exposições, deixando à margem a vida operária das fábricas e os aspectos desiguais que constituíam as modernas invenções. As nações apresentavam-se reduzidas a um protótipo de suas "grandezas", numa seleção criteriosa daquilo que os governos e suas elites elegiam exibir.

As exposições representaram uma forma de silenciamento em relação às reivindicações dos trabalhadores e às lutas dos movimentos sociais, ainda que algumas questões tenham sido incorporadas às exposições de forma pontual. Esses foram os casos de pavilhões ou espaços específicos destinados às exposições de mulheres e de negros, primeiramente organizados nas exposições estadunidenses. Esses foram os

11 KUHLMANN Jr., Moysés. "As Exposições universais e a utopia do controle social". XVII Simpósio Nacional de História. Anais do XVII Simpósio Nacional de História. São Paulo, julho 1993, pp.169.

12 PEREIRA, M. C. da S. A Participação do Brasil nas Exposições Universais: Uma arqueologia da modernidade brasileira. Revista Projeto, São Paulo, № 139, p. 83-90, 1992. 
casos do "Departamento de mulheres", inaugurado em 1876, na Exposição da Filadélfia, ${ }^{13}$ e do "Departamento de pessoas de cor", apresentado em 1884, na Exposição Internacional do Algodão, em Nova Orleães. ${ }^{14}$ Esses pavilhões traziam à tona preocupações sociais, agrupando de forma específica reivindicações desses segmentos da sociedade, mas sem ampliar qualquer leque de demandas políticas ou incorporá-las à realidade dos eventos.

Portanto, pretendemos neste artigo analisar essa participação dos países a partir daquilo que se escolheu representar e, no caso do Brasil, identificando que interesses estiveram em destaque nesses eventos. Certamente, não foram ali exibidos os negros e os indígenas, o trabalho camponês ou as diversas realidades das províncias como parte de uma unidade nacional, realidade essa que se pretendia portadora de determinados ideais e interesses.

\section{As Exposições Nacionais no Brasil}

Os debates sobre o atraso brasileiro e a não inserção em uma política de industrialização se colocaram durante algum tempo como entraves à participação do Brasil nos eventos universais, onde as preocupações de determinados segmentos da elite apareciam no debate sobre como seria apresentada a modernidade de uma sociedade escravista no exterior. Essa modernidade supunha aspectos ideológicos próprios de uma época, que criavam um repertório de práticas políticas para associá-las ao que significava "ser moderno" 15 Ser partícipe deles significava compartilhar dos signos do progresso material e das transformações advindas do processo industrial, de um modelo de desenvolvimento econômico, do qual esses eventos tornaram-se fortes porta-vozes.

Malgrado as dificuldades nas tentativas brasileiras de realizar uma exposição nacional no país no período entre os anos 1840 e 1850, em 1861 realizou-se a primeira, em circunstâncias festivas e com a presença do Imperador e sua família e, evidentemente, gozando do seu total estímulo. Nessa primeira exibição foram expostos matérias-primas, produtos manufaturados, invenções diversas, recursos naturais, apresentados por seus respectivos expositores, oriundos de todas as regiões do país. $O$

${ }^{13}$ CORDATO, Mary Frances. Toward a New Century: women and the Philadelphia Centennial Exhibition, 1876. The Pennsylvania Magazine of History and Biography. V. 107, N.1 (Jan.1983), p. 113-115.

${ }^{14}$ PFEFFER, Miki. "Mr. Chairman and Fellow American Citizens": African American Agency at the World's Industrial and Cotton Centennial Exposition in New Orleans, 1884-1885, Louisiana History: The Journal of the Louisiana Historical Association, Vol. 51, No. 4 (Fall 2010), p. 456.

15 HARDMAN, Francisco Foot. Trem fantasma: a modernidade na selva. São Paulo: Cia das Letras, 1988; PESAVENTO, Sandra J. Exposições universais: espetáculos da modernidade no século XIX. São Paulo: Editora Hucitec, 1997. 
evento foi marcado ainda por uma enorme quantidade de visitantes que vinha de todos os lugares do Império. Aberta na data de aniversário de D. Pedro II, manteve-se em alta procura, tendo sido realizada na Escola Central no Largo de São Francisco, na Corte. ${ }^{16}$

Nas exposições, as cidades-sede tornavam-se também fantasias do progresso. Em "Vitrines do Progresso", Neves mostrou como essas exposições mereceram uma aclimatação naquele ambiente "desfavorável e hostil" da capital do Império, em 1861, quando as belezas do progresso e da modernidade se tornavam acessíveis aos olhos de todos e "confirmados assim em seu destino de 'desterrados em sua própria terra', os cariocas comtemplam estas fantásticas exibições e nelas aprendem a lição de um futuro que ilusoriamente situa seu país no rol das nações civilizadas". ${ }^{17}$ Atraídos a esses espaços públicos de exibições os visitantes se tornavam elemento fundamental para a difusão dos princípios didáticos contidos nas exposições, carregados dos conteúdos ideológicos representados por elas.

O particular fomento a exposições foi intenção declarada pela Sociedade Auxiliadora da Indústria Nacional (SAIN) desde sua fundação, e foi sob os seus cuidados e os do Imperial Instituto Fluminense de Agricultura que elas se realizaram partir de 1861. A Sociedade também organizava a exibição brasileira nas exposições universais no exterior. Esse intuito expresso pela SAIN revelava os fundamentos de sua criação, tendo o estímulo à indústria como bandeira, a premissa de que dela deveriam vir os maiores incentivos à produção, amparada pela responsabilidade que assumiu desde sua criação como instância consultiva do governo em assuntos relativos à concessão de privilégios, patentes, prêmios etc. ${ }^{18}$

As exposições nacionais realizadas pelo Brasil nos anos 1860 antecederam a participação do país nos eventos internacionais: em 1861, preparatória para a Exposição universal de Londres em 1862, e em 1866, preparando a participação na Exposição universal de Paris em 1867. Ao longo desse período exposições provinciais foram incentivadas, tanto por interesses regionais de fomento à indústria local ou para prepararem as exposições nacionais. Em 1866 a exposição nacional contou ainda com o

${ }^{16}$ ELKIN, Noah C. Promoting a new Brazil: National Expositions and images of modernity,1861-1922. Tese (Doutorado em História) - School-New Brunswick Rutgers, The State University of New Jersey. New Brunswick, 1999; REZENDE, Lívia Lazzaro. The Raw and the Manufactured: Brazilian Modernity and National Identity as Projected in International Exhibitions (1862-1922). Tese (Doutorado em História do Design) - Royal College of Art. London, 2010; MARTINS, Mônica. O espetáculo da economia: a Primeira Exposição Nacional da Indústria no Império do Brasil, em 1861, Topoi (Rio J.), Rio de Janeiro, v. 21, n. 44, p. 497-517, maio/ago. 2020.

17 NEVES, Margarida. As Vitrines do Progresso. Rio de Janeiro: PUC-RJ/FINEP/CNPq, 1986, p. 17.

18 BARRETO, Patrícia Regina Corrêa. Sociedade Auxiliadora da Indústria Nacional: Templo carioca da Palas Atenas. Doutorado em História das Ciências, Técnicas e Epistemologia. Programa de PósGraduação em História das Ciências, Técnicas e Epistemologia da UFRJ. Rio de Janeiro: UFRJ, 2009. 
empenho em divulgar as grandezas do Império estando o país envolvido na Guerra do Paraguai (1864-1870).

A partir desses elementos podemos questionar: exatamente o que abrangia uma exposição nacional no Brasil? Que interesses "nacionais" de fato estiveram nelas representados?

Um importante estudo sobre a participação brasileira nas exposições universais foi o de Werneck Silva em sua tese As arenas Pacíficas do Progresso, realizado nos anos 1980. Debruçando-se sobre o entendimento das origens desses eventos nacionais, Werneck Silva reportou-se à tradição das feiras coloniais no Brasil. No seu entendimento essas feiras remetiam-se à tradição medieval europeia, que subsistiram à época moderna, mantendo-se como importantes espaços comerciais e impulsionadoras, ao mesmo tempo, da vida urbana. Se no Brasil se manteve um aparato das feiras de menores proporções e com suas singularidades - que ele identifica como correlatas e parcialmente sincrônicas às europeias -, ao mesmo tempo elas retratariam uma vida comercial voltada aos interesses externos, pautando-se na ideia de um mercado interno fraco e pouco consolidado que não teria dado lugar a uma maior robustez das feiras, como ocorreu na Europa. Segundo ele, embora elas apresentassem diferenças regionais, mantinham práticas semelhantes às feudais e algumas atividades mercantis, mas eram dominadas no Brasil pelas "práticas escravistas coloniais", privilegiando os interesses metropolitanos externos.

A perspectiva de Silva a respeito dessa tradição no Brasil pautou-se, no aspecto teórico, na abordagem de Caio Prado Júnior ${ }^{19}$ e, em grande medida, ele dialoga com a interpretação que Eulália Lobo fez sobre as feiras coloniais a partir de sua relação com as cidades. ${ }^{20} \mathrm{E}$ neste ponto um aspecto chama a atenção frente às pesquisas desenvolvidas nos últimos anos, visto que essas feiras coloniais expressavam a força do comércio de determinados bens para as cidades e povoados, como demonstrado pelo peso das trocas interprovinciais. A importância crescente dos setores ligados ao abastecimento, conforme tem sido tema de diversos estudos da história econômica e social, nos mostra hoje os limites dessa interpretação sobre o significado exercido pelas atividades comerciais regionais no período. ${ }^{21}$ Neste mesmo artigo citado, Eulália Lobo mostra a formação de um mercado interno de relativa importância em Minas e como

\footnotetext{
19 JUNIOR, Caio Prado. Formação do Brasil contemporâneo. 12ª Ed. São Paulo: Brasiliense, 1972.

20 LOBO, Eulália Maria Lahmeyer. El papel comercial y financeiro de las ciudades em la América Latina de los siglos XVIII y XIX, in: HARDOY, J; MORSE, R; SHAEDEL, R. Ensayos Histórico-sociales sobre la urbanización en America Latina. Buenos Aires: CLACSO; Ediciones Siap, 1978, p. 219-248.

${ }^{21}$ FRAGOSO, João Luís R. Homens de grossa aventura: acumulação e hierarquia na praça mercantil do Rio de Janeiro, 1790-1830. Rio de Janeiro: Civilização Brasileira, 1998.
} 
outras regiões que se expandiam suas atividades comerciais abasteciam Minas Gerais, algumas delas possuidoras de importantes feiras, como o caso do Rio de Janeiro. ${ }^{22}$ As feiras de gado, por exemplo, se constituíram em pontos de comércio altamente controlados e vigiados, com importância singular na vida econômica das regiões, por vezes gerando mesmo impacto decisivo nas relações sociais e culturais locais. ${ }^{23}$ É possível que pesquisas futuras possam identificar nas diferentes províncias e regiões processos de convergência ou continuidade de tradições entre feiras e exposições locais, algo que não identificamos hoje nos eventos nacionais realizados na Corte.

O esforço em associar esses eventos do século XIX às experiências coloniais me parece menos uma identificação de aspectos genuínos dessas feiras que tenham se mantido na criação das exposições nacionais, e mais um esforço em associar o caso brasileiro à experiência europeia das feiras medievais. Entretanto, desde a criação da SAIN, em 1827, todas as menções à organização de exposições das indústrias estavam muito menos associadas a qualquer experiência anterior das feiras e mercados no Brasil e mais a uma iniciativa que tomava como referência as práticas já desenvolvidas em outros países nos oitocentos, qual fosse, de expor nacionalmente os frutos da sua produção e invenção e fomentar a concorrência como estímulo produtivo através de exposição e premiação. ${ }^{24}$ Esses eram espetáculos de exibição e catalogação, não diretamente de venda de produtos, como o que caracterizava as feiras.

Essa iniciativa está muito mais atrelada a uma preocupação que marcou a SAIN desde sua fundação, relacionada ao estímulo ao desenvolvimento técnico associado à produção agrícola no Brasil, com fomento às exposições e a premiações de invenções. Apesar da França ter inaugurado com a Feira de 1798 um modelo de evento comercial associado a um espaço de divertimento, o modelo da Exposição da Indústria proposto pela Grã-Bretanha em 1851 se tornou um padrão para esse formato de exibição

\footnotetext{
22 Lobo, op. cit., p. 230.

${ }^{23}$ A Feira de Capuame, na Bahia, a maior feira colonial de gado, pode ser tomada como um exemplo. Sobre o tema ver os estudos: MOTT, Luiz. "Subsídios à história do pequeno comércio no Brasil", Revista de História, vol. 53, n. 105, 1976; HENRIQUE, Juliana da Silva. A Feira de Capuame: pecuária, territorialização e abastecimento (Bahia, século XVIII). Dissertação de Mestrado, Programa de PósGraduação em História Econômica. São Paulo: USP, 2014.

24 SILVA, José Luiz Werneck da. Isto é o que me parece: a Sociedade Auxiliadora da Indústria nacional (1827-1904) na formação social brasileira. A conjuntura de 1871 até 1877. 2 vols. Dissertação (Mestrado em História), Programa de Pós-Graduação em História, Universidade Federal Fluminense, 1979, p. 78. A prática de premiar invenções era realizada pela Sociedade Auxiliadora da Industria Nacional desde a sua fundação e foi expandida durante as exposições. Premiar era apresentar, valorizar e incentivar aspectos diversos da produção naquele momento. Parte da arrecadação da Sociedade era destinada à concessão e prêmios para estímulo à agricultura, a artistas ou ao chamado fabricante industrioso, para financiar edições de publicações avulsas sobre artes industriais ou à compra de publicações pertinentes ao tema.
} 
industrial. ${ }^{25}$ Esses eventos uniam num mesmo espaço as atividades comerciais e as de diversão, incrementadas tanto por um apelo de cunho mais elitista quanto dedicada aos propósitos de se tornar popular. Apesar das feiras francesas terem sido exemplares para as futuras exposições universais, cada vez mais elas se distanciariam daquela concepção de comércio direto e fomento local desempenhado pelas feiras do período moderno. ${ }^{26}$

A participação do Brasil nas exposições foi tema de reflexão, tanto pelos impactos do acesso ao conhecimento industrial e tecnológico interno como pela circulação de ideias nesses espaços onde os países se apresentavam. ${ }^{27}$ No entanto, foi na SAIN que esses debates apareceram de forma mais aprofundada, onde se colocaram de fato dilemas inerentes às vantagens e desvantagens de inserção do Brasil nesses eventos, com um modelo de produção agrícola, escravista e com pouco investimento em melhoramentos técnicos que pudessem ser apresentados externamente. Venceu a decisão do governo e dos produtores que enxergaram as vantagens comerciais desses espetáculos para setores da economia nacional e a possibilidade de o Império se lançar ao mundo, projetando para fora e para dentro uma ideia de unidade nacional. ${ }^{28}$

Apesar de criada como uma sociedade privada, pois seus recursos eram obtidos a partir de contribuições, a SAIN trabalhou de forma muito próxima ao Ministério da Agricultura, Comércio e Obras Públicas, logo após o seu estabelecimento, em 1860. Além de instância consultora, ela realizava pareceres e revisava pedidos de patentes, de tecnologias de diferentes tipos, desde máquinas agrícolas, químicas ou ferroviárias. Portanto, ela foi uma instituição importante no fomento à todas as melhorias produtivas no país e, no bojo dessa intenção, esteve também a participação junto à exibição da produção brasileira no exterior.

A ela coube a organização da participação do Brasil nas maiores Exposições Universais no século XIX. Isso porque a partir dos anos 1880 passou a concorrer com

25 GOLDMAN, Flávio. Exposições universais e Diplomacia Pública. Brasília: Fundação Alexandre de Gusmão, 2016, p. 36. A exposição de 1798 se distinguiu especialmente por patrocinar a mistura entre o objetivo comercial e o entretenimento de forma mais grandiosa e espetacular, distanciando-se daquela cultura secular das feiras associadas a motivos religiosos, tão característicos da pujança das cidades europeias na era moderna.

${ }^{26}$ FINDLING e PELLE, op. cit., 1990, p.3-9.

27 FERREIRA, Cristina Araripe. Difusão do conhecimento científico e tecnológico no Brasil na segunda metade do século XIX: a circulação do progresso nas exposições universais e Internacionais. Tese de Doutorado em História das Ciências e da Saúde. Rio de Janeiro: Fundação Oswaldo Cruz, 2011 ; BARBUY, Heloísa. O Brasil vai a Paris em 1889: um lugar na Exposição Universal. Anais do Museu Paulista. São Paulo, n. ser, v. 4, p.211-240, dez. 1996, p. 211-240; GUIMARÃES, Lúcia. Exposições. In VAINFAS, R (Dir.). Dicionário do Brasil Imperial (1822-1889). Rio de Janeiro: Objetiva, 2002, pp. 252253.

28 CARVAlHO, José Murilo de. A construção a Ordem e Teatro de Sombras. 4ª ed. Rio de Janeiro: Civilização Brasileira, 2008. 
ela a Associação Centro da Lavoura e do Comércio do Rio de Janeiro, que esteve à frente não apenas de exposições do café nos Estados Unidos, países da América e Europa, como esta última organizou o catálogo e a apresentação do Brasil na Exposição Universal Centenária do Algodão, em Nova Orleães, em 1884. ${ }^{29}$

\section{As exposições e o fomento econômico: uma análise das fontes}

Essa reflexão sobre o lugar das exposições nacionais nos remete aqui a dois pontos fundamentais na análise sobre esses primeiros eventos organizados no Brasil. Primeiro, como os interesses econômicos de setores ligados à exportação foram aqueles que se destacaram no fomento do governo às exposições e, a partir deles, se capitaneava o que o governo divulgava como "interesse nacional". As exposições no Brasil também se constituíram em espaços excludentes para aspectos relacionados aos diversos segmentos da sociedade, sendo esse caráter nacional restrito ao interesse de alguns setores mais abastados da economia. Em segundo lugar, nesses primeiros anos tanto vemos relatos explicitamente comemorativos sobre a participação do Brasil nas exposições, como havia também o lugar para a crítica política e, mesmo os documentos encomendados pelo governo, acabaram também sendo reveladores dos limites impostos pelas escolhas econômicas deste.

A seguir analiso uma crítica política apresentada pela Semana llustrada, contraposição às análises festivas geralmente apresentadas na época. A referida Revista foi publicada e circulou na Corte entre 1860 e 1876, tendo como editor o desenhista e gráfico alemão Henrique Fleiuss e seus projetos gráficos representaram uma verdadeira inovação na imprensa brasileira do século XIX. A revista trabalhava com humor e sátira, foi pioneira na integração da caricatura ao texto informativo dos jornais. ${ }^{30}$

Os periódicos se constituem como fontes extremamente ricas para a análise sobre o pensamento que circulava, as críticas e elogios à participação brasileira. A Semana llustrada e, particularmente, essa sátira apresentada aqui, nos possibilita analisar a crítica a esse aspecto nacional da representação brasileira nas exposições,

29 FAIRALL, Herbert. The World's Industrial and Cotton Centennial Exposition, New Orleans, 18841885. Iowa City, IA: Republican Publishing Co., 1885; Centro da Lavoura e Comércio, Brazilian Coffee. Opinions of Scientists on Its Merit, published by the Association Centro da Lavoura e Comércio do Rio de Janeiro for distribution at the World's Industrial and Cotton Centennial Exposition of New Orleans. New York: E. P. Coby, 1885.

30 Ver: ANDRADE, Joaquim Marçal Ferreira. A trajetória de Henrique Fleiuss, da Semana llustrada: subsídios para uma biografia. In: KNAUSS, Paulo (org.) Revistas llustradas: modos de ler e ver o Segundo Reinado. Rio de Janeiro: Mauad X: FAPERJ, 2011. 
questionando-se quem e quais interesses de fato estavam sendo representados nesses eventos.

Outra importante fonte sobre as exposições nacionais são os Relatórios produzidos com a finalidade de descrever com minúcias aspectos diversos relativos aos eventos, em solicitação dos organizadores e do governo. Entretanto, nesses documentos foram descritas muitas vezes críticas ou apresentação de problemas e limites relacionados a esses eventos. Assim, apresento os relatórios do Júri das exposições da década de 1860, com as análises a respeito dos limites da economia brasileira do período, apresentando ainda questionamentos às decisões econômicas adotadas pelo governo imperial.

\section{Exposições Nacionais no Brasil dos anos 1860: A colheita das graças e a do café...}

Em 5 de janeiro de 1862, a Revista Semana llustrada publicava na seção Contos do Rio de Janeiro, conto que bem reproduzia o olhar desconfiado e irônico sobre aqueles que representavam o Brasil e sua produção na exposição londrina. Satirizava-se o lugar dos grandes proprietários como porta vozes da produção nacional, por meio do diálogo entre os cidadãos Crispim e Frasão, caracterizado pela ironia e pela crítica política:

\section{DIÁLOGO ENTRE OS CIDADÃOS CRISPIM E FRASÃO}

Crispim: Ora até que a final! Desatou-se o nó górdio da questão londrina. Ainda bem!

Frasão: O nó górdio?

Crispim: Sim, senhor. E desta vez ninguém dará que a montanha gerou um rato, por minh'alma!

Frasão: Estou em branco, compadre: não entendo patavina de todo este teu engrelorio. Fallas-me em tantas cousas a um tempo! Explica-te melhor. Qual foi a montanha que não abortou um camundongo!

Crispim: Foi o governo.

Frasão: O governo!?

Crispim: Admiras-te? Fazes como eu fiz; mas é tal qual. Sabes que estava de há muito, na ordem do dia a solução de um problema complicadissmo. Tratava-se, nem mais nem menos, de nomear uma commissão brasileira para a Exposição Universal de Londres. O caso era grave, gravíssimo!

Frasão: Salus populi!

Crispim: Credo, compadre, não involas o Espirito Santo em tão profanas intrigas!

Crispim: Tens razão. Neste caso direi que o governo fez como Diogenes: sahiu pipa, accendeu a lanterna e foi por essas ruas procurando dignamente na Albion o Imperio de Santa Cruz.

Frasão: E achou? 
Crispim: Tres! A folha official assim se exprimiu, dando conta da notícia; "Os Srs. Carvalho Moreira, Barão de Mauá e João Manoel Pereira da Silva foram encarregados de representar o Brazil na Exposição de Londres".

Frasão: Ui, compadre; que é isso que diz? "Foram encarregados de representar o Brasil" Por elles é que a Europa vae avaliar nossa industria e lavoura?

Crispim: Parece que sim.

Frasão: Homem essa! Achava melhor que se mandasse o algodão, a carnaúba e...

Crispim: E os inhames. Tambem eu penso assim.

Frasão: Mandar três homens representar o Brazil na Exposição Universal!! Crispim: Não são três homens; são três figurões. E' para que o mundo saiba que no Brazil a colheita das graças não é menos profusa do que a do café.

Frasão: E considerem esses três cavalheiros como productos... vegetaes, animaes ou...

Crispim: São productos do reino mineral, creio eu. ${ }^{31}$

A comicidade do conto não esconde a fina sátira à forma como esses nomes foram escolhidos e como o governo elegia alguns dos seus quadros de confiança para representar o país. Através da definição de que "no Brasil a colheita das graças não é menos profusa do que a do café", exibia-se uma crítica à política dos privilégios e mercês que concediam o lugar proeminente a alguns junto ao governo. Para bom entendedor a referência direta aos interesses da família imperial ilustrada pelas terras da freguesia de Santa Cruz: "sahiu pipa, accendeu a lanterna e foi por essas ruas procurando dignamente na Albion o Imperio de Santa Cruz". Seria mesmo positivo que depois do imbróglio fossem os três cavalheiros aqueles designados a representar 0 Brasil no exterior? Não seria melhor mandar os produtos ao invés dos homens? Assim seguia a sátira do conto. Analisemos nossos três indicados.

João Manoel Pereira da Silva ${ }^{32}$, escritor e membro do partido conservador, era de família abastada da Vila de Iguaçu, na província do Rio de Janeiro, e estudou direito em Paris. De volta ao Brasil, fez-se escritor e deputado entre os anos 1840 e a década de 1880, terminando a carreira política como senador. Francisco Inácio de Carvalho Moreira, titulado Barão de Penedo em 1864, exerceu advocacia e doutorou-se na Universidade de Oxford. No Brasil fora deputado e exerceu carreira diplomática, representando o Brasil junto aos Estados Unidos a partir de 1852; depois na Europa, onde desempenhou papel fundamental na intermediação do Brasil junto à Inglaterra na

\footnotetext{
${ }^{31}$ Semana Illustrada, $n^{\circ}$ 56, 5 de janeiro de 1862, p.442-443.

32 Biografia do autor em: <http://www.academia.org.br/academicos/j-m-pereira-da-silva/biografia $>$. Acesso em 24/09/2018.
} 
Questão Christie. ${ }^{33}$ Representou o Brasil na Exposição Universal de 1862, em Londres. Irineu Evangelista de Souza foi o primeiro Barão de Mauá, em 1854, depois Visconde de Mauá, ${ }^{34} \mathrm{em}$ 1874. Investidor nas atividades comercial, fabril e bancária, foi um dos mais destacados industriais brasileiros do império, inclusive em ferrovias.

A par das diferenças, o que esses três nomes tinham em comum eram sua ligação com a Sociedade Auxiliadora da Indústria Nacional, como quadros do pensamento intelectual de Estado e ligados à produção e à política. A Revista llustrada exaltava o Imperador e o seu editor, Henrique Fleuiss, conhecido por sua postura patriótica, não poupava críticas aos políticos e àqueles que bajulavam o governo em troca de benesses, ao longo de suas páginas.

Irineu Evangelista de Souza é um caso muito exemplar para a sátira. A sua trajetória empresarial a partir da montagem da fábrica na Ponta d'Areia foi extremamente importante para aproximá-lo dos homens do governo, ao mesmo tempo em que recebia benefícios dessa aproximação. Esse estreitamento de laços garantiu vantagens, por exemplo, na aprovação de compras pelo governo da sua produção, tendo recebido ainda 300 contos de empréstimo governamental em 1847 para a ampliação do seu empreendimento. ${ }^{35}$ A mesma fábrica receberia, na Exposição Nacional de 1861, a medalha de prata na categoria 'machinas e aparelhos'. ${ }^{36}$ Apesar de tudo, suas ações em causa própria também o tornaram um sujeito impopular, visto por muitos com desconfiança.

A ironia aos nomes certamente fazia jus ao papel crítico que a revista desempenhava em relação aos rumos políticos, tanto nas questões urbanas quanto nas políticas nacionais de incentivo à produção, por exemplo. Em 1860, a mesma revista fez um destaque bem ilustrativo da imagem que mostrava o Brasil com uma lavoura promissora e bem desenvolvida, enquanto os outros dois pés da economia enfrentavam falta de estímulos do governo:

- Este quadro é para a exposição da Assembleia Geral. Sabes o que representa?

- Não, sinhô.

- Pois ouve, moleque: é o Brasil sustentado por três grandes troncos - a agricultura, comércio e indústria. Porém o comércio tem muitas folhas e poucos frutos, e a indústria está completamente seca. Só a agricultura floresce, mas sabe Deus como é um corpo sem braços. ${ }^{37}$

${ }^{33}$ MENDONÇA, Renato Firmino. Um diplomata na Corte de Inglaterra: o Barão de Penedo e sua época. Brasília: Conselho Editorial do Senado Federal, 2006.

${ }_{34}$ MARCHANT, Anyda. Viscount Mauá and the Empire of Brazil: a biography of Irineu Evangelista de Souza; 1813-1889. Berkeley; Los Angeles: University of California, 1965.

35 SILVA, op. cit., 1979, p.71-72.

${ }^{36}$ LUZ, Nícia Vilela. A Luta pela industrialização no Brasil. São Paulo: Editora Alfa-Ômega, 1978, p. 77.

${ }^{37}$ Semana llustrada, $n^{\circ} 15,24$ de março de 1861, p. 8. 
Vê-se a profunda crítica ao caráter pouco diversificado do investimento na produção brasileira, com exuberância da agricultura vis-à-vis às outras esferas produtivas, sugerindo a centralidade do apoio governamental à lavoura. Essa avaliação será vista mais adiante também nos relatórios sobre as exposições. No caso desse diálogo, tratava-se de uma crítica contundente naquele momento que antecedia a primeira exposição. Uma velada e irônica menção à escravidão aparece ainda na resposta: "Não, sinhô. Pois ouve, Moleque”, referência a tudo o que o país não queria mostrar no exterior, ou seja, seu lado escravista. ${ }^{38}$ Por outro lado, no conto publicado em 1862 questionam-se aqueles representantes do país na sua força produtiva no exterior, na sua indústria e na sua lavoura. Dois deles eram personagens de clara trajetória política e diplomática, enquanto Mauá destacava-se por seu empenho na esfera fabril. Ao indagar se o Brasil deveria enviar produtos ao invés dos homens, o conto satirizava o fato de irem lá os "figurões"; os que mais representavam os interesses do governo ao invés dos braços trabalhadores da nação. Finalizavam ainda com 0 humor ácido: seriam eles produtos animais, vegetais ou minerais?

Essa pouca diversificação econômica foi descrita no Relatório do Júri produzido após a Exposição nacional de 1861, um documento de vastas informações acerca das condições produtivas das províncias naquele momento. O relatório não se ateve apenas a uma descrição do que foi exposto, mas seu valor singular está na avaliação qualitativa que faz sobre a economia brasileira como um todo, suas condições, seus limites e suas perspectivas. Um primeiro aspecto é a percepção das condições da indústria no Brasil atrelada a uma "inatividade predominante", que não daria vazão ao desenvolvimento de maior produção comercial e industrial, apesar da existência de vasta riqueza natural. Aliás, a riqueza natural é utilizada como argumento para talvez se constituir num empecilho à indústria, levando a uma acomodação não produtiva, argumento importante do pensamento liberal na perspectiva da iniciativa produtiva dos indivíduos. A comissão das exposições em Pernambuco, no entanto, foi além nas alegações:

Obtemperando ao preceito de indicar os possíveis melhoramentos industriaes nas províncias, limita-se a comissão a ponderar, que não existindo verdadeiramente indústria fabril, e não podendo ella êxistír em quanto o juro dos capitaes e o preço do trabalho forem tão caros, nada mais se pode indicar do que a necessidade de reunirem os bons cidadãos todos os seus esforços para remover as causas que obstam à existência desta indústria. A acção destas mesmas causas, entorpece a lavoura,

38 Idem, p. 13. Moleque era o companheiro do Dr. Semana, personagens principais da revista: "O Moleque, que se caracterizava pelos comentários sempre maliciosos, tratava o Dr. Semana por Nhonhô, vestia-se a caráter, usava libré, como era próprio dos pequenos escravos que trabalhavam como pajens nas casas das pessoas ricas da Corte." 
influindo de um modo funesto na qualidade e na quantidade de seus produtos, vindo a ser o melhoramento principal e comum a todas as nossas industrias, a diminuição dos juros dos capitães e o aumento das forças produtoras. ${ }^{39}$

É à iniciativa dos "bons cidadãos" o apelo a um desenvolvimento das condições para os melhoramentos "industriais", no sentido lato que o termo assumiu no século XIX. No entanto, aí se nota como esses eventos foram importantes numa avaliação econômica sobre o desenvolvimento produtivo das províncias e como eles contribuíram para uma ação mais coesa e organizada dos produtores e industriais nas décadas seguintes. Os relatórios eram também denúncias sobre o estado geral da produção, constituíam-se em veículos críticos da situação econômica, ainda que não transpareça uma ação direta mais contundente de crítica ao governo nestes primeiros documentos. Também se ressalta aí como vários artigos de usos medicinais tinham valor comercial para as províncias, ${ }^{40}$ o que corrobora a percepção da importância do comércio interprovincial de gêneros nacionais.

O relator chama a atenção para a extrema importância da flora brasileira, suas plantas e minerais, para a fabricação de medicamentos e para tratamentos terapêuticos, alertando para a relevância em se investir nesse conhecimento e nessa produção. Neste ponto, ressaltava-se o quanto são subestimadas as riquezas naturais brasileiras e 0 quanto se gasta com importação de produtos que são produzidos no Brasil: "Que extenso commercio não fariam essas províncias, se taes matérias fossem aproveitadas com uma abundância proporcional à profusão com que a natureza as dotou!". ${ }^{41}$

Foram assinaladas as madeiras brasileiras da construção civil, naval e marcenaria, apresentadas em quantidade e variedade nas exposições, e o relatório destaca que grande parte das madeiras usadas nas construções das casas e nos móveis era importada do exterior. Também se realçou a quantidade de óleos produzidos no Amazonas para uso culinário, terapêutico, iluminação, fabricação de sabão, para uso medicinal e pintura; era na iluminação de origem estrangeira da capital do império ou para a produção de sabão importada em grande parte da gordura bovina do Rio da Prata. Cunha se ressente de não haver maior estímulo à exploração dessa riqueza natural, que poderia movimentar o comércio entre as províncias, especialmente da ausência de uma adequada exploração de recursos do Amazonas e do Pará, que estimulariam o comércio de cabotagem com as demais províncias do Império. Para

39 CUNHA, Antonio Luiz Fernandes da. Documentos officiaes relativos à Exposição Nacional de 1861. Rio de Janeiro: Typographia do Diario do Rio de Janeiro, 1862, p. 26.

40 Idem, p. 27. 
estas duas províncias teriam restado apenas a exportação de borracha e do cacau para o exterior, mas sem grande participação no comércio nacional, estando a população pobre majoritariamente dedicada à extração da borracha. ${ }^{42}$

O relatório mostra o empenho em investir em técnicas para o desenvolvimento da agricultura e da exploração de recursos minerais diversos, podendo gerar efeito multiplicador em vários setores da economia. Essa avaliação é ainda mais contundente quando se ressente do que poderia ser aplicado para desenvolver uma indústria algodoeira no solo brasileiro. A própria SAIN já havia dedicado, em 1861, várias páginas de análises no Auxiliador sobre os meios e as possibilidades para o desenvolvimento da agricultura algodoeira, seguindo o exemplo dos Estados Unidos. Cunha mostra ao longo do relatório que o algodão, sendo o terceiro artigo de exportação do Brasil, estava muito abaixo do seu potencial econômico; sendo assim, se o Vale do Amazonas e o do Rio São Francisco investissem na produção, o Brasil alcançaria a produção do Vale do Mississipi. Ao contrário disso, em sua opinião, havia apenas inciativas de produção de tecidos de algodão em manufaturas grosseiras derivadas de técnicas rudimentares de fabricação em Minas, no Rio de Janeiro e na Bahia.

O café e o açúcar eram os dois gêneros mais importantes na permuta por produtos importados. Contudo, embora todas as províncias produzissem café, apenas o do Rio de Janeiro era responsável por cerca de $2 / 3$ da produção nacional. Sendo o principal produto exportador, para essa produção se dirigia o maior investimento do governo, e neste ponto o relatório também realçava o limite dessa concentração de incentivos ao explicitar que qualquer crise em sua produção representaria grave risco à economia brasileira como um todo.

Não obstante a grande importância do produto, a imprensa da época retratou a pouca participação dos fazendeiros cafeicultores nas exposições, o que foi atribuído à baixa qualidade do café brasileiro em relação aos grãos do exterior: "A inferioridade do nosso café nos mercados consumidores, não resulta de sua manipulação, porém sim da espécie, da cultura, e do modo de o colher e secar". ${ }^{43}$ Novamente, voltava-se à questão do caráter técnico, do emprego de mecanismos mais modernos de produção agrícola, tema fundamental nos debates da SAIN e nos propósitos do empenho em estimular as invenções.

Já as amostras de tabaco, consumidas no mundo inteiro e fortemente comercializadas pelo Brasil, estiveram em grande número na exposição: "Os visitantes

\footnotetext{
41 Idem, ibid.

42 Idem, p. 29.
} 
tiveram occasião de observar grande copia de caixas de charutos, massos de cigarros cobertos com diversas materias, fumo em folha, em rolo, trançado, em forma de tijolo etc., e fabricado em pó e em rapé". Quase todas as províncias enviaram amostras de tabaco, destacando-se o fumo de Borba e de algumas localidades de São Paulo. Segundo o relatório o tabaco produzido pela Bahia era muito estimado em muitos mercados consumidores, reputado por muitos como o melhor depois do de Havana.

Vinhos, licores, aguardente de cana, fumo, chá, produtos agrícolas diversos também foram exibidos na exposição e apresentavam importante valor comercial. No entanto, "O café, o assúcar, o tabaco, o algodão, e, em segundo logar, a borracha, o matte e o cacáo, são, como fica indicado, os unicos gêneros que damos em troca dos artigos manufacturados e das substancias allimenticeas, que recebemos por importação". ${ }^{44} \mathrm{O}$ milho, principal causa da devastação das matas e florestas brasileiras, era em larga medida importado dos Estados Unidos e Portugal, e foi exibido em espigas soltas. No entanto, era produzido pela Província do Maranhão que o comercializa com as províncias do Pará, Rio Grande do Sul e a Corte.

No mesmo sentido a exposição de 1866 deixou à mostra a ênfase na manutenção da dependência em relação às matérias primas vindas do exterior, que tornavam altos os custos de alguns produtos, como a produção de sapatos. Em uma das correspondências a Machado de Assis o Conde de La Hure, tratando com descrição minuciosa o trabalho dos sapateiros, afirma que quase toda a matéria-prima correspondente à produção dos sapatos no Brasil tinha que vir do exterior, devido ou aos altos custos dos produtos internos ou à sua má qualidade..$^{45} \mathrm{E}$ não era sem razão a preocupação, dado que se destacavam na fabricação brasileira produtos como calçados e roupas, com manufaturas instaladas em diversos pontos das províncias, especialmente no Rio de Janeiro.

Vemos, no entanto, que a Exposição Nacional de 1866 apresentou limites em relação à anterior. A entrada do Brasil na Guerra do Paraguai tornou mais difícil o envolvimento das províncias. Por outro lado, isso não representou menor estímulo do governo ao evento, que teve significativo aporte de recursos, conforme demonstrado na tabela 3. O catálogo da Exposição apresentado em Paris mostrava esse esforço

\footnotetext{
43 Idem, p. 32.

44 Idem, p. 35.
} 
brasileiro, indicando a situação singular em que o país se encontrava. Ainda assim, a presença efetiva do país na França com sua exibição mostrava a prioridade atribuída a esses eventos nos anos 1860 e o quanto o governo brasileiro considerava comercialmente importante essa participação. Segundo a informação apresentada na introdução do citado catálogo brasileiro, as condições de apresentação do Brasil foram muito desfavoráveis em razão da sua participação na Guerra da Tríplice Aliança e o próprio catálogo apresentava-se como um "apanhado imperfeito" das riquezas nacionais. ${ }^{46}$

Nessa perspectiva, o catálogo O Império Do Brasil na Exposição Universal de 1867 em Paris, apresentava uma descrição das condições do comércio brasileiro interno, por cabotagem interprovincial, e do comércio externo. ${ }^{47}$ Os quadros sobre 0 comércio brasileiro de importação e exportação mostram as razões da preocupação do governo e de segmentos dos setores agrícolas com a qualidade das mostras, visto a importância que os produtos assumiam no exterior. Apesar desses dados já terem sido analisados em outros estudos econômicos sobe o século XIX, é importante retomarmos o significado que era atribuído ao Brasil nas relações comerciais internacionais e o peso da exportação para o país. Nessa pequena amostra de 1864 e 1865 fica explícita a proeminência britânica, seguida pela França, e os Estados Unidos já aparecem como o terceiro maior importador de produtos brasileiros, condição que se ampliará na década seguinte, especialmente devido à exportação e café.

Tabela 1- Países que concorreram para a importação entre 1864-65

\begin{tabular}{|c|c|c|}
\hline $\begin{array}{c}\text { Países que } \\
\text { concorreram para a } \\
\text { importação entre } \\
\mathbf{1 8 6 4 - 6 5}\end{array}$ & Valor em réis & $\begin{array}{c}\text { Razão por } \\
\text { cento }\end{array}$ \\
\hline Grã-Bretanha & $63.538: 015 \$$ & 48,29 \\
\hline França & $30.646: 087 \$$ & 23,29 \\
\hline República do Prata & $11.700: 203 \$$ & 8,89 \\
\hline Estados Unidos & $6.325: 937 \$$ & 4,81 \\
\hline Portugal & $6.289: 431 \$$ & 4,78 \\
\hline Cidades Hanseaticas & $4.941: 910 \$$ & 3,74 \\
\hline
\end{tabular}

${ }^{45}$ ASSIS, Machado de. Correspondência de Machado de Assis: tomo II, 1870-1889 / coordenação e orientação Sergio Paulo Rouanet; reunida, organizada e comentada por Irene Moutinho e Sílvia Eleutério. Rio de Janeiro: Academia Brasileira de Letras, 2009. (Coleção Afrânio Peixoto; v. 92), p. 380-393.

46 O Império do Brasil na Exposição de 1867 em Paris. Rio de Janeiro: Typographia Universal de Laemmert, 1867, p. 58-61. De acordo com o catálogo os valores de venda nesse período foram, entre os três mais importantes produtos de exportação: café $64.144: 555$; algodão $31.558: 635 \$$ e açúcar 16.282:124\$.

47 MARCONDES, Renato Leite. "O mercado brasileiro do século XIX: uma visão por meio do comércio de cabotagem", Revista de Economia Política, v. 32, n. 1 (126), p. 142-166, São Paulo, Jan-Mar. 2012, p. 142-166. 


\begin{tabular}{|c|c|c|}
\hline Outros Estados & $8.152: 574 \$$ & 6,20 \\
\hline Total & $131.594: 157 \$$ & 100,00 \\
\hline
\end{tabular}

Fonte: O Império do Brasil na Exposição de 1867..., 1867, p. 57.

Tabela 2- Países que consumiram os produtos do Brasil em 1864-65

\begin{tabular}{|l|c|c|}
\hline $\begin{array}{l}\text { Países que } \\
\text { consumiram os } \\
\text { produtos do Brasil } \\
\text { em 1864-65 }\end{array}$ & Valor em réis & $\begin{array}{r}\text { Razão por } \\
\text { cento }\end{array}$ \\
\hline Grã-Bretanha & $59.498: 604 \$$ & 42,18 \\
\hline França & $18.826: 611 \$$ & 13,35 \\
\hline Estados Unidos & $18.530: 865 \$$ & 13,14 \\
\hline Portugal & $7.422: 964 \$$ & 5,26 \\
\hline Repúblicas do Prata & $5.496: 902 \$$ & 3,89 \\
\hline Outros Estados & $31.292: 524 \$$ & 22,18 \\
\hline Total & $141.068: 470 \$$ & 100,00 \\
\hline
\end{tabular}

Fonte: O Império do Brasil na Exposição de 1867...,1867, p. 58.

E os produtos apresentados na Exposição Universal de Paris, em 1867, mostraram que o Brasil reafirmou no cenário internacional seu lugar de país com forte potencial agrícola, evidenciado através dos comentados pavilhões e, sobretudo, pelas exposições e premiações do café, da madeira e do algodão brasileiros. ${ }^{48}$ Dentre os gêneros de maior exportação brasileira estavam o café, algodão, açúcar, couros secos e salgados, fumo, cacau, erva-mate, aguardente, cabelo de animais, crina e lã, goma elástica, jacarandá, ouro e diamantes e outros gêneros de consumo não classificados.

As críticas que salpicavam ao longo desses documentos mostram aspectos menos comemorativos e empolgados relacionados a essas exposições e o olhar daqueles que acompanhavam a presença brasileira. Essas fontes atuaram como um importante espelho sobre as ações do governo e a política econômica aplicada, apresentando os limites da produção nacional e a concentração produtiva no setor agrícola, especialmente o cafeeiro.

Conforme já salientado, a presença de visitantes e a participação geral de exibidores nesses eventos foi significativa. Apesar de todas as dificuldades, a Exposição Nacional de 1866 apresentou expressivo aumento tanto no número de visitantes, quanto de expositores e de produtos apresentados. Salta aos olhos a explosiva procura pela participação nos eventos no curto espaço de cinco anos, como podemos ver pelos dados comparativos abaixo entre as duas primeiras exposições nacionais. Visualiza-se como o governo ampliou significativamente a aplicação de recursos públicos para a realização da exposição de 1866, mesmo com o envolvimento do país na Guerra: 
Tabela 3- Comparação entre as Exposições de 1861 e 1866

\begin{tabular}{|l|c|c|}
\hline & $\begin{array}{l}\mathbf{1}^{\mathbf{a}} \\
\text { Nacional Exposição } \\
\text { Indústria (1861) }\end{array}$ & $\begin{array}{l}\mathbf{2}^{\mathbf{a}} \\
\text { da }\end{array}$ \\
\hline $\begin{array}{l}\text { Nacional da Indústria } \\
\text { (1866) }\end{array}$ \\
\hline $\begin{array}{l}\text { Púmero de } \\
\text { expositores }\end{array}$ & 9.862 & 20.128 \\
\hline $\begin{array}{l}\text { Número de } \\
\text { visitantes }\end{array}$ & 1.136 & 2.374 \\
\hline $\begin{array}{l}\text { Valores gastos } \\
\text { pelo governo }\end{array}$ & 18.000 & 53.000 \\
\hline
\end{tabular}

Dados informados em: CUNHA, 1862; O Império do Brasil na Exposição de 1867..., 1867.

A década seguinte foi de fortalecimento dessas relações internacionais do Brasil em sua participação nas Exposições, bem representado pela icônica participação do Brasil na Exposição Universal da Filadélfia, em 1876, onde o Imperador esteve pessoalmente abrindo o evento com o presidente americano e recebido com muito prestígio. ${ }^{49}$ Consolidavam-se os ventos do bem-sucedido comércio de café com os Estados Unidos, que só se ampliava, mas também de um conjunto de práticas do governo alicerçando os caminhos para essas boas relações comerciais na América que vinham sendo colocadas em ação desde a década anterior.

Portanto, as exposições nacionais foram assumidas como referências de apresentação de significativa parcela da produção nacional, especialmente aquela mais diretamente interessada na exportação ou em ampliar a visibilidade do país no exterior. Foram esses setores que se apropriaram, portanto, da noção de "nacionalidade" em defesa dos próprios interesses naquele momento, capitaneando os ideais de modernidade e de progresso tão caros a esses eventos internacionais, utilizando-os também a partir de seus simbolismos internos. A unidade nacional poderia se desmoronar face à concorrência entre as províncias pelos melhores lugares de exibição, mas era garantida em conformidade com os simbolismos imperiais voltados à propaganda do país no exterior.

48 Goldman, op. cit., p.66.

49 PESAVENTO, Sandra J. Imagens da Nação, do Progresso e da Tecnologia: A Exposição Universal de Filadélfia de 1876, Anais do Museu Paulista, São Paulo, v. 2, p. 151-167, 1994; SCHWARCZ, Lilia Moritz. "Exposições Universais: festas do trabalho, festas do progresso. In: As barbas do imperador: D. Pedro II - um monarca nos trópicos. São Paulo: Cia das Letras, 1998; CRIBELLI, Teresa. "O Império das Palmeiras, os Estados Unidos descobrem o Brasil, 1789-1892" in: MARTINS, Ana Cecilia Impellizieri \& SOCHACZEWSKI, Monique (org.) As Descobertas do Brasil: o olhar estrangeiro na construção da imagem do Brasil. Editora Casa da Palavra, Rio de Janeiro, 2014. 
O que se apresentava era, outrossim, um recorte do país, selecionado e premiado para se exibir. A escravidão não ia ao exterior, e alguns relatos indicam que os cativos também não podiam entrar nas exposições na Corte. Indígenas de nações diversas foram apropriados nestes espaços como elementos exóticos para apreciação pública no exterior.

No contexto econômico de ampliação das relações comerciais internacionais, elas desempenharam função significativa na expansão das trocas comerciais e financeiras entre o Brasil e os outros países, reivindicando ainda um lugar que o caracterizasse cultural e politicamente no cenário diplomático internacional. $O$ crescimento na participação das províncias, dos produtores, expositores e no número de visitantes reafirma o potencial que elas assumiram no nível econômico, tanto quanto se difundiram no nível ideológico. Os espetáculos da indústria assumiam a forma e o discurso tanto da nação que desejava ser mostrada como daquela que era silenciada.

A promessa da modernidade foi uma importante sedução ideológica promovida pelas exposições do século XIX. A análise apresentada por Marshall Berman nos apresentou as dualidades da modernidade: num polo, o modernismo das nações industrializadas, fruto das transformações políticas e econômicas que se materializaram nas fábricas e nas ferrovias e, no outro polo, um modernismo que se caracterizou pelo atraso e subdesenvolvimento. Neste ponto, "o modernismo do subdesenvolvimento é forçado a se construir de fantasias e sonhos de modernidade, a se nutrir de uma intimidade e luta contra miragens e fantasmas", 50 num processo de incorporação e reconstrução das ideias, inserindo-se entre as novidades dos modernos centros e as realidades locais. A dualidade da modernidade reside exatamente nisso, "o modernismo, onde se desenvolve, assume um caráter fantástico, porque é forçado a se nutrir não da realidade social, mas de fantasias, miragens e sonhos". ${ }^{51}$ No bojo desse Brasil que traçava o caminho da modernidade pairavam as utopias que o ancoravam ao seu lugar dentro das trocas internacionais e o mantinham mergulhado na escravidão.

\section{REFERÊNCIAS}

ANDERSON, Benedict. Comunidades imaginadas. São Paulo: Companhia das Letras, 2008.

ASSIS, Machado de. Correspondência de Machado de Assis: tomo II, 1870-1889 / coordenação e orientação Sergio Paulo Rouanet; reunida, organizada e comentada por Irene Moutinho e

50 BERMAN, Marshall. Tudo que é sólido desmancha no ar. A aventura da modernidade. São Paulo: Companhia das Letras, 1986, p. 219.

51 Idem, p. 223. 
Sílvia Eleutério. Rio de Janeiro: Academia Brasileira de Letras, 2009. (Coleção Afrânio Peixoto; v. 92), p. 380-393.

BANCROFT, Hubert Howe. The book of the fair: an historical and descriptive presentation of the world's Science, art and industry, as viewed through the Columbian Exposition at Chicago in 1893. Chicago/São Francisco: The Bancroft Company, Publishers, 1893, part 1.

BARBUY, Heloísa. O Brasil vai a Paris em 1889: um lugar na Exposição Universal. Anais do Museu Paulista. São Paulo, n. ser, v. 4, p.211-240, dez. 1996.

BARRETO, Patrícia Regina Corrêa. Sociedade Auxiliadora da Indústria Nacional: Templo carioca da Palas Atenas. Doutorado em História das Ciências, Técnicas e Epistemologia. Programa de Pós-Graduação em História das Ciências, Técnicas e Epistemologia da UFRJ. Rio de Janeiro: UFRJ, 2009.

BERMAN, Marshall. Tudo que é sólido desmancha no ar. A aventura da modernidade. São Paulo: Companhia das Letras, 1986.

CARVALHO, José Murilo de. A construção a Ordem e Teatro de Sombras. $4^{\mathrm{a}}$ ed. Rio de Janeiro: Civilização Brasileira, 2008.

CENTRO da Lavoura e Comércio, Brazilian Coffee. Opinions of Scientists on Its Merit, published by the Association Centro da Lavoura e Comércio do Rio de Janeiro for distribution at the World's Industrial and Cotton Centennial Exposition of New Orleans. New York: E. P. Coby, 1885.

CORDATO, Mary Frances. Toward a New Century: women and the Philadelphia Centennial Exhibition, 1876. The Pennsylvania Magazine of History and Biography. V. 107, N.1 (Jan.1983), p. 113-135.

CRIBELLI, Teresa. "O Império das Palmeiras, os Estados Unidos descobrem o Brasil, 17891892" in: MARTINS, Ana Cecilia Impellizieri \& SOCHACZEWSKI, Monique (org.) As Descobertas do Brasil: o olhar estrangeiro na construção da imagem do Brasil. Editora Casa da Palavra, Rio de Janeiro, 2014.

CUNHA, Antonio Luiz Fernandes da. Documentos officiaes relativos à Exposição Nacional de 1861. Rio de Janeiro: Typographia do Diario do Rio de Janeiro, 1862.

FAIRALL, Herbert. The World's Industrial and Cotton Centennial Exposition, New Orleans, 18841885 lowa City, IA: Republican Publishing Co., 1885.

FERREIRA, Cristina Araripe. Difusão do conhecimento científico e tecnológico no Brasil na segunda metade do século XIX: a circulação do progresso nas exposições universais e Internacionais. Tese de Doutorado em História das Ciências e da Saúde. Rio de Janeiro: Fundação Oswaldo Cruz, 2011.

FILIPOVÁ, Marta. "The Margins of Exhibitions and Exhibitions Studies", in: FILIPOVÁ, M. (Ed.) Cultures of International Exhibitions 1840-1940. Burlington: Ashgate, 2015.

FINDLING, John E.; PELLE, Kimberly D. Historical Dictionary of World's Fairs and Expositions, 1851-1988. Westport, Connecticut: Greenwood Press, 1990.

FRAGOSO, João Luís R. Homens de grossa aventura: acumulação e hierarquia na praça mercantil do Rio de Janeiro, 1790-1830. Rio de Janeiro: Civilização Brasileira, 1998. GOLDMAN, Flávio. Exposições universais e Diplomacia Pública. Brasília: Fundação Alexandre de Gusmão, 2016. 
GRAHAM, Richard. Construindo uma nação no Brasil do século XIX: visões novas e antigas sobre classe, cultura e Estado, Diálogos, DHI/UEM, v. 5, n. 1. p. 11-47, 2001.

GREENHALGH, Paul. Ephemeral Vistas: the Expositions Universelles, Great Exhibitions and World's Fairs, 1851-1939. Manchester: Manchester University Press, 1988.

GUIMARÃES, Lúcia. Exposições. In VAINFAS, R (Dir.). Dicionário do Brasil Imperial (18221889). Rio de Janeiro: Objetiva, 2002, pp. 252-253.

HARDMAN, Francisco Foot. Trem fantasma: a modernidade na selva. São Paulo: Cia das Letras, 1988.

HENRIQUE, Juliana da Silva. A Feira de Capuame: pecuária, territorialização e abastecimento (Bahia, século XVIII). Dissertação de Mestrado, Programa de Pós-Graduação em História Econômica. São Paulo: USP, 2014.

HOBSBAWM, Eric, The Age of Revolution,1789-1898. New York: Vintage Books, 1996. HOBSBAWM, E. Nações e nacionalismo desde 1780. $7^{\mathrm{a}}$ ed. Rio de Janeiro: Paz e Terra, 2012. KUHLMANN Jr., Moysés. "As Exposições universais e a utopia do controle social". XVII Simpósio Nacional de História. Anais do XVII Simpósio Nacional de História. São Paulo, julho 1993, pp.169-170.

JUNIOR, Caio Prado. Formação do Brasil contemporâneo. 12ª Ed. São Paulo: Brasiliense, 1972.

LOBO, Eulália Maria Lahmeyer. El papel comercial y financeiro de las ciudades em la América Latina de los siglos XVIII y XIX, in: HARDOY, J; MORSE, R; SHAEDEL, R. Ensayos Históricosociales sobre la urbanización en America Latina. Buenos Aires: CLACSO; Ediciones Siap, 1978, p. 219-248.

LUZ, Nícia Vilela. A Luta pela industrialização no Brasil. São Paulo: Editora Alfa-Ômega, 1978.

MARCHANT, Anyda. Viscount Mauá and the Empire of Brazil: a biography of Irineu Evangelista de Souza; 1813-1889. Berkeley; Los Angeles: University of California, 1965.

MARCONDES, Renato Leite. "O mercado brasileiro do século XIX: uma visão por meio do comércio de cabotagem”, Revista de Economia Política, v. 32, n. 1 (126), p. 142-166, São Paulo, Jan-Mar. 2012.

MARTINS, Mônica. O espetáculo da economia: a Primeira Exposição Nacional da Indústria no Império do Brasil, Topoi, Rio de Janeiro, v.21, n.44, p. 457-517, maio-ago./2020.

MENDONÇA, Renato Firmino. Um diplomata na Corte de Inglaterra: o Barão de Penedo e sua época. Brasília: Conselho Editorial do Senado Federal, 2006.

MOTT, Luiz. "Subsídios à história do pequeno comércio no Brasil", Revista de História, vol. 53, n. $105,1976$.

NEVES, Margarida. As Vitrines do Progresso. Rio de Janeiro: PUC-RJ/FINEP/CNPq, 1986.

PESAVENTO, Sandra J. Imagens da Nação, do Progresso e da Tecnologia: A Exposição Universal de Filadélfia de 1876, Anais do Museu Paulista, São Paulo, v. 2, p. 151-167, 1994.

PESAVENTO, Sandra J. Exposições universais: espetáculos da modernidade no século XIX. São Paulo: Editora Hucitec, 1997.

PFEFFER, Miki. "Mr. Chairman and Fellow American Citizens": African American Agency at the World's Industrial and Cotton Centennial Exposition in New Orleans, 1884-1885, Louisiana History: The Journal of the Louisiana Historical Association, Vol. 51, No. 4 (Fall 2010). 
PLUM, Werner. Exposições no século XIX: espetáculos da transformação sociocultural. Bonn: Friedrich-Ebert-Stiftung, 1979.

O IMPÉRIO do Brasil na Exposição de 1867 em Paris. Rio de Janeiro: Typographia Universal de Laemmert, 1867.

SANJAD, Nelson. Exposições internacionais: uma abordagem historiográfica a partir da América Latina, Revista História, Ciências, Saúde - Manguinhos, v.24, n.3, jul.-set. 2017, p.785-826.

SCHWARCZ, Lilia Moritz. "Exposições Universais: festas do trabalho, festas do progresso. In: As barbas do imperador: D. Pedro II - um monarca nos trópicos. São Paulo: Cia das Letras, 1998.

Semana llustrada: história de uma inovação editorial. Secretaria Especial de Comunicação Social. Prefeitura da Cidade do Rio de Janeiro. Rio de Janeiro: Secretaria, 2007.

SEMANA ILUSTRADA, n¹5, 24 de março de 1861, p. 8.

SEMANA ILUSTRADA, no 56, 5 de janeiro de 1862, p.442-443.

SILVA, José Luiz Werneck. As arenas pacíficas do Progresso. Tese de Doutorado em História. 2 vols. Niterói: Universidade Federal Fluminense, 1992.

SILVA, José Luiz Werneck da. Isto é o que me parece: a Sociedade Auxiliadora da Indústria nacional (1827-1904) na formação social brasileira. A conjuntura de 1871 até 1877.2 vols. Dissertação (Mestrado em História), Programa de Pós-Graduação em História, Universidade Federal Fluminense, 1979.

\section{NOTAS DE AUTOR}

\section{CONTRIBUIÇÃO DE AUTORIA}

Mônica de Souza Nunes Martins - Concepção. Coleta de dados, Análise de dados, Elaboração do manuscrito, revisão e aprovação da versão final do trabalho

\section{FINANCIAMENTO}

O presente trabalho foi realizado com apoio da Coordenação de Aperfeiçoamento de Pessoal de Nível Superior Brasil (CAPES) - Código de financiamento 001. Programa Professor Visitante no Exterior 2018-2019, Edital 45/2017. A pesquisa tem apoio da FAPERJ, através da Programa Apoio a Grupos Emergentes do Estado do Rio de Janeiro, Edital 04/2016.

\section{CONSENTIMENTO DE USO DE IMAGEM}

Não se aplica

\section{APROVAÇÃO DE COMITÊ DE ÉTICA EM PESQUISA \\ Não se aplica}

\section{CONFLITO DE INTERESSES}

Declaro não haver conflito de interesse.

\section{LICENÇA DE USO}

Este artigo está licenciado sob a Licença Creative Commons CC-BY. Com essa licença você pode compartilhar, adaptar, criar para qualquer fim, desde que atribua a autoria da obra.

\section{HISTÓRICO}

Recebido em: 29-06-2020

Aprovado em: 08-03-2021 